Article

\title{
Investigation of Regeneration Mechanisms of Aged Solar Salt
}

\author{
Julian Steinbrecher ${ }^{1, *(\mathbb{D}}$, Alexander Bonk ${ }^{1} \mathbb{D}$, Veronika Anna Sötz ${ }^{2,3}$ and Thomas Bauer ${ }^{2} \mathbb{D}$ \\ 1 Institute of Engineering Thermodynamics, German Aerospace Center (DLR), D-70569 Stuttgart, Germany; \\ Alexander.Bonk@dlr.de \\ 2 Institute of Engineering Thermodynamics, German Aerospace Center (DLR), D-51147 Cologne, Germany; \\ veronika.soetz@th-deg.de (V.A.S.); Thomas.Bauer@dlr.de (T.B.) \\ 3 Research Center Modern Mobility, Technology Campus Plattling, D-94447 Plattling, Germany \\ * Correspondence: julian.steinbrecher@dlr.de
}

check for updates

Citation: Steinbrecher, J.; Bonk, A.; Sötz, V.A.; Bauer, T. Investigation of Regeneration Mechanisms of Aged Solar Salt. Materials 2021, 14, 5664. https://doi.org/10.3390/ma14195664

Academic Editors: Francisco de Paula Montero Chacón and Juan Carlos Serrano-Ruiz

Received: 27 August 2021

Accepted: 25 September 2021

Published: 29 September 2021

Publisher's Note: MDPI stays neutral with regard to jurisdictional claims in published maps and institutional affiliations.

Copyright: (c) 2021 by the authors. Licensee MDPI, Basel, Switzerland. This article is an open access article distributed under the terms and conditions of the Creative Commons Attribution (CC BY) license (https:/ / creativecommons.org/licenses/by/ $4.0 /)$.

\begin{abstract}
The scope of our study was to examine the potential of regeneration mechanisms of an aged molten Solar Salt (nitrite, oxide impurity) by utilization of reactive gas species (nitrous gases, oxygen). Initially, aging of Solar Salt $\left(60 \mathrm{wt} \% \mathrm{NaNO}_{3}, 40 \mathrm{wt} \% \mathrm{KNO}_{3}\right)$ was mimicked by supplementing the decomposition products, sodium nitrite and sodium peroxide, to the nitrate salt mixture. The impact of different reactive purge gas compositions on the regeneration of Solar Salt was elaborated. Purging the molten salt with a synthetic air $\left(\mathrm{p}\left(\mathrm{O}_{2}\right)=0.2 \mathrm{~atm}\right)$ gas stream containing $\mathrm{NO}(200 \mathrm{ppm})$, the oxide ion concentration was effectively reduced. Increasing the oxygen partial pressure $\left(\mathrm{p}\left(\mathrm{O}_{2}\right)=0.8 \mathrm{~atm}\right.$, 200 ppm NO) resulted in even lower oxide ion equilibrium concentrations. To our knowledge, this investigation is the first to present evidence of the regeneration of an oxide rich molten Solar Salt, and reveals the huge impact of reactive gases on Solar Salt reaction chemistry.
\end{abstract}

Keywords: thermal energy storage; concentrating solar power (CSP); molten nitrate salt; thermal stability; liquid-gas reactions

\section{Introduction}

Thermal energy storage with molten nitrate salts at $565^{\circ} \mathrm{C}$ is currently employed in several Concentrating Solar Power (CSP) plants to provide dispatchable and renewable electricity in the MW-scale. To increase the solar-to-power conversion efficiency, elevating the maximum operating temperature is one possible strategy [1,2]. For a nitrate based molten salt storage system, chemical stability is challenged at temperatures beyond $565{ }^{\circ} \mathrm{C}$ and thus effort needs to be made to maintain thermal properties of this sensible heat storage material. The decomposition and equilibrium reactions of a nitrate-based molten salt has extensively been investigated over the past decades and a variety of decomposition mechanisms are reported [3-6]. It is widely accepted that in a first step nitrate ions $\left(\mathrm{NO}_{3}{ }^{-}\right)$ compose to form nitrite ions $\left(\mathrm{NO}_{2}{ }^{-}\right)$under the release of oxygen (Equation (1)).

$$
\mathrm{NO}_{3}^{-} \rightleftharpoons \mathrm{NO}_{2}^{-}+1 / 2 \mathrm{O}_{2} \text {. }
$$

In the second step, the nitrite ion further decomposes to form oxide ions. A reaction, most commonly referred to as a possible decomposition mechanism for nitrite, is the formation of metal oxide, accompanied by the evolution of $\mathrm{NO}$ and $\mathrm{NO}_{2}$ (Equation (2)).

$$
2 \mathrm{NO}_{2}^{-} \rightleftharpoons \mathrm{O}^{2-}+\mathrm{NO}+\mathrm{NO}_{2}
$$

Beside these ions, the evolution of several reactive gas species, namely oxygen, nitrogen and nitrous oxide $\left(\mathrm{N}_{2} \mathrm{O}\right)$ has been discovered [7]. It has to be emphasized that the exact stoichiometry of Equation (2) has not been determined experimentally and may also depend on atmospheric composition. Additionally, at different temperatures, other reaction paths may become favorable [8,9]. Nevertheless, the influence of nitrous gases on 
the nitrite-oxide equilibrium becomes more tangible through Equation (2). In this regard, Sötz et al. reported the stabilization of molten Solar Salt with a purge gas flow containing nitrous gases at temperatures of $600{ }^{\circ} \mathrm{C}$ and even $620^{\circ} \mathrm{C}$ in terms of stable nitrate-nitriteand low oxide ion concentrations.

In this study, the positive effect of the stabilizing gases is tested to its limits. More specifically, the reduction of high oxide ion levels $(0.15 \mathrm{wt} \%$ or $1 \mathrm{~mol} \%)$ in Solar Salt-based mixtures (60 $\mathrm{wt} \% \mathrm{NaNO}_{3}, 40 \mathrm{wt} \% \mathrm{KNO}_{3}$ ) by reversing Equation (2), is demonstrated. These mixtures are artificially aged by adding unusually high concentrations of nitriteand oxide ions ( $10 \mathrm{~mol} \%$ and $1 \mathrm{~mol} \%$, respectively) and the effect of different purge gas compositions ( $20 \%$ and $80 \% \mathrm{O}_{2}$, with and without $200 \mathrm{ppm} \mathrm{NO}$ ) on the salt chemistry are investigated. The synthetically aged Solar Salt mixtures represent extreme conditions of decomposed Solar Salt beyond the tolerable level in practical applications. Increasing the operating temperature, the threat of salt decomposition becomes more likely and, so far, active control of reaction Equation (2) has not been sufficiently addressed in the literature. In this paper the reduction of oxide ion concentration is defined as regeneration, which is the process to convert synthetically altered Solar Salt to Solar Salt with a tolerable low level of oxide and nitrite ions. In other words, this work presents a change of perception, where decomposition products are intentionally added to the salt melt, in order to enable the investigation of a recovery/regeneration mechanism, which has not been investigated experimentally yet.

\section{Materials and Methods}

To investigate salt regeneration, synthetically altered Solar Salt was produced by mixing $\mathrm{NaNO}_{3}$ (Merck, Darmstadt, Hesse, Germany, purity $>99 \%$ ), $\mathrm{KNO}_{3}$ (Merck, purity $>99 \%$ ), and $\mathrm{Na}_{2} \mathrm{O}_{2}$ (Merck, purity $>95 \%$ ) prepared in a moisture-free atmosphere and $\mathrm{NaNO}_{2}$ (Merck, Darmstadt, Hesse, Germany, purity $>99 \%$ ), according to the desired composition listed in Table 1. The cation content in all experiments, was fixed to the one of the Solar Salt composition ( $\mathrm{Na} 65.5 \mathrm{~mol} \%$; K $35.5 \mathrm{~mol} \%$ ). Each of the experiments is labeled according to their salt and purge gas composition (see Figure 1).

Table 1. List of experiments of this work (and literature). Labels are specified with regard to salt composition and purge gas composition. All salts exhibit Na/K ratios equal to that of ideal Solar Salt mixture (Na $65.5 \mathrm{~mol} \%: \mathrm{K} 35.5 \mathrm{~mol} \%$ ).

\begin{tabular}{|c|c|c|c|c|c|c|}
\hline \multirow[t]{2}{*}{ Label } & \multicolumn{3}{|c|}{ Anion Content (mol \%) } & \multicolumn{3}{|c|}{ Purge Gas (100 mL/min) } \\
\hline & Nitrate & Nitrite & Peroxide & $\mathbf{N}_{2}$ & $\mathrm{O}_{2}$ & NO \\
\hline Ref/20_0 [a] & 100 & 0 & 0 & $80 \mathrm{vol} \%$ & $20 \mathrm{vol} \%$ & 0 \\
\hline $\operatorname{Ref} / 20 \_200[\mathrm{~b}]$ & 100 & 0 & 0 & $80 \mathrm{vol} \%$ & $20 \mathrm{vol} \%$ & 200 ppm \\
\hline Ox/20_0 & 99 & 0 & 1 & $80 \mathrm{vol} \%$ & $20 \mathrm{vol} \%$ & 0 \\
\hline Nit-Ox/20_0 & 89 & 10 & 1 & $80 \mathrm{vol} \%$ & $20 \mathrm{vol} \%$ & 0 \\
\hline Nit-Ox/20_200 & 89 & 10 & 1 & $80 \mathrm{vol} \%$ & $20 \mathrm{vol} \%$ & $200 \mathrm{ppm}$ \\
\hline Ref/80_0 & 100 & 0 & 0 & $20 \mathrm{vol} \%$ & $80 \mathrm{vol} \%$ & 0 \\
\hline Ox/80_0 & 99 & 0 & 1 & $20 \mathrm{vol} \%$ & $80 \mathrm{vol} \%$ & 0 \\
\hline Nit-Ox/80_0 & 89 & 10 & 1 & $20 \mathrm{vol} \%$ & $80 \mathrm{vol} \%$ & 0 \\
\hline Ox/80_200 & 99 & 0 & 1 & $20 \mathrm{vol} \%$ & $80 \mathrm{vol} \%$ & 200 ppm \\
\hline Nit-Ox/80_200 & 89 & 10 & 1 & $20 \mathrm{vol} \%$ & $80 \mathrm{vol} \%$ & $200 \mathrm{ppm}$ \\
\hline
\end{tabular}

[a,b] Reference experiments already published by Sötz et al. [7].

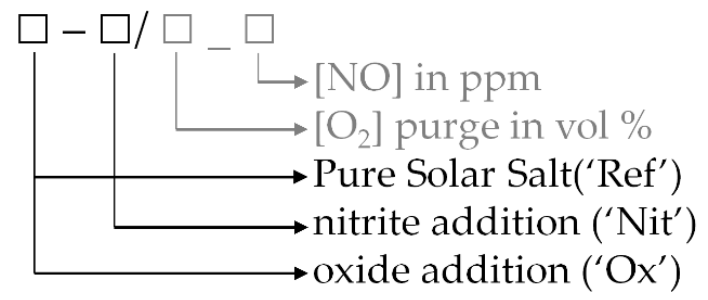

Figure 1. Experiment labeling according to salt composition and purge gas used. 
For each experiment an autoclave test rig was loaded with $100 \mathrm{~g}$ of salt mix contained in an $\mathrm{Al}_{2} \mathrm{O}_{3}$ crucible. The autoclave test rig is temperature controlled and purged with a gas flow, and adjusted with calibrated flow meters. A detailed description of the experimental setup is given by Bonk et al. [10]. In order to remove moisture and carbon dioxide, each of the salt mixtures is heated to $120{ }^{\circ} \mathrm{C}$ for at least $24 \mathrm{~h}$ under a flow of synthetic air (5.0 grade, Linde Gas). Subsequently, $\mathrm{Na}_{2} \mathrm{O}_{2}$ is added to the salt and the desired purge gas flow $(100 \mathrm{~mL} / \mathrm{min})$ is adjusted from mixing $\mathrm{O}_{2}, \mathrm{~N}_{2}$ and a reference gas containing $1000 \mathrm{ppm} \mathrm{NO}$ in $\mathrm{N}_{2}$ (all 5.0 grade, Linde gas). The salt is stirred and heated ( $2 \mathrm{~K} / \mathrm{min}$ ) to the target temperature $\left(600^{\circ} \mathrm{C}\right)$ and the purge gas flow is adjusted according to the desired composition (see Table 1). Upon reaching $600{ }^{\circ} \mathrm{C}$, the first salt sample is collected $(\mathrm{t}=0 \mathrm{~h}$ ). Over the course of the isothermal experiments $(\sim 1200 \mathrm{~h})$, salt samples are extracted and analyzed to monitor salt composition (see upcoming sub-chapter for details).

To reveal the anion (and cation) content of the salt samples, ion chromatography is utilized. For ion chromatography (IC) a Metrohm model 930 Compact IC Flex is used. About $125 \mathrm{mg}$ of the salt sample is dissolved in ultrapure water $(500 \mathrm{~mL}$, HiPerSolv, VWR, Darmstadt, Germany) and analyzed. A detailed description of the experimental procedure and calibration is given elsewhere [10]. Chromate was measured in order to monitor undesired side reactions between the steel parts and the molten salt. The limit for quantitative detection of chromate ions accounts to $0.2 \mathrm{mg} / \mathrm{L}$ or $0.05 \mathrm{~mol} \%$ in a salt sample. Standard deviation for IC analysis was accessed via a five-fold measurement of a representative sample composition $\left(\mathrm{c}\left(\mathrm{NO}_{3}{ }^{-}\right)=140.13 \mathrm{mg} / \mathrm{L}, \mathrm{c}\left(\mathrm{NO}_{2}{ }^{-}\right)=26.43 \mathrm{mg} / \mathrm{L}\right.$, $\left.\mathrm{c}\left(\mathrm{CrO}_{4}{ }^{2-}\right)=0.72 \mathrm{mg} / \mathrm{L}\right)$.

To identify additional cationic species (other than sodium and potassium) arising from steel corrosion (iron, chromium, nickel), an iCE 3000 series atomic adsorption spectrometer from Thermo Fisher Scientific (Waltham, Massachusetts, USA) was utilized. In a standardized procedure, about $50 \mathrm{mg}$ of the salt sample are dissolved in $50 \mathrm{~mL}$ of ultrapure water including $0.5 \mathrm{~mL}$ of $69 \% \mathrm{HNO}_{3}$ and $0.5 \mathrm{~mL}$ of a $10 \% \mathrm{CsCl}$ solution. Calibration was performed with standard solutions (Roth, certified reference material; (iron $(1003.0 \pm 2.2 \mathrm{mg} / \mathrm{L}$; chromium $(1000.9 \pm 3.1 \mathrm{mg} / \mathrm{L}$; nickel $(1001.8 \pm 3.5 \mathrm{mg} / \mathrm{L}))$ for iron, chromium and nickel and freshly prepared for the desired concentration range (1-5 mg/L).

The oxide and carbonate contents are determined by inert gas acid base titration (Metrohm Titrando 800, Herisau, Switzerland). Regardless of the specific oxide ion species actually present in the melt $\left(\mathrm{O}_{2}{ }^{-}, \mathrm{O}_{2}{ }^{2-}, \mathrm{O}^{2-}\right)$, all are summarized and expressed as $\mathrm{O}^{2-}$ values in this work. About $500 \mathrm{mg}$ of each salt sample was dissolved in $160 \mathrm{~mL}$ ultrapure water and titrated with $0.01 \mathrm{M} \mathrm{HCl}$ (Titrisol standard solution). Calibration of the $\mathrm{HCl}$ titrant was performed by multiple titrations of a known amount of pre dried $\mathrm{Na}_{2} \mathrm{CO}_{3}$ (Merck, Darmstadt, Hesse, Germany, purity $>99.5 \%$ ). The oxide ion concentration of the molten salt is calculated back from the measured hydroxide $\left(2 \mathrm{OH}^{-}\right.$converted to $\left.1 \mathrm{O}^{2-}\right)$ and carbonate $\left(1 \mathrm{CO}_{3}{ }^{2-}\right.$ converted to $\left.1 \mathrm{O}^{2-}\right)$ concentrations, obtained from acid base titration [10-12]. The carbonates are likely to be formed after sample extraction, since the purge gases are of high purity and leak rates of the test rig are low. It is reasonable and already reported that oxide ions react with atmospheric carbon dioxide before or during titration $[10,13]$. In the presence of nitrite, the found carbonate ion concentration is significantly lower (10-20\%) when compared to the true value. In order to take this systematic error into account, error bars of the oxide ion concentration contain the maximum error for the carbonate detection and for this reason are not symmetric. The detection limit with regard to salt composition was below $0.1 \mathrm{~mol} \% \mathrm{O}^{2-}$.

For mol fractions of each ionic species all uncertainties are combined via quadratic error propagation and represented as error bars in the figures (see Tables S1-S3). Overall, the most relevant post analysis methods were IC and titration to monitor the nitrite and oxide level for the Solar Salt regeneration. Other measurements were supplementary to monitor undesired side reactions with some steel parts. 


\section{Results and Discussion}

\subsection{Behavior of an Oxide Rich Nitrate Melt under Various Conditions}

In the following, changes in the anion content of the molten salt over the course of the experiment are discussed in order to reveal a potential influence of different purge gas compositions on the molten salt chemistry. In order to avoid an incorrect interpretation of the experimental results, the effect of each reaction parameter needed to be analyzed with caution. For clarity, the different experiments listed in Table 1 are categorized and discussed separately in a twofold manner. To exclude the effect of the nitrate-nitrite equilibrium, for the first set the results of molten salt purged with $\mathrm{p}\left(\mathrm{O}_{2}\right)=0.2 \mathrm{~atm}$ are discussed. In the second step, experiments with a purge gas containing $\mathrm{p}\left(\mathrm{O}_{2}\right)=0.8 \mathrm{~atm}$ are discussed.

The summarized data of experiments performed under $\mathrm{p}\left(\mathrm{O}_{2}\right)=0.2 \mathrm{~atm}$ expressed as anion concentrations over time, is illustrated in Figure 2. Reference experiments of pure Solar Salt already published are marked orange and named according to the applied purge gas (Ref/20_0, Ref/20_200) [7]. Within $200 \mathrm{~h}$, all experiments exhibited a steady concentration of nitrates and nitrites. The molar fraction of nitrate stabilized between 89.0, 89.3, $89.6( \pm 0.1) \mathrm{mol} \%$ (Ox/20_0, Nit-Ox/20_200, Nit-Ox/20_0). Similarly, the nitrite concentration equilibrated at 10.4, 9.8, $9.7( \pm 0.1) \mathrm{mol} \%$ respectively. In general, these results agree with previously reported Solar Salt equilibrium data [7,14-16].
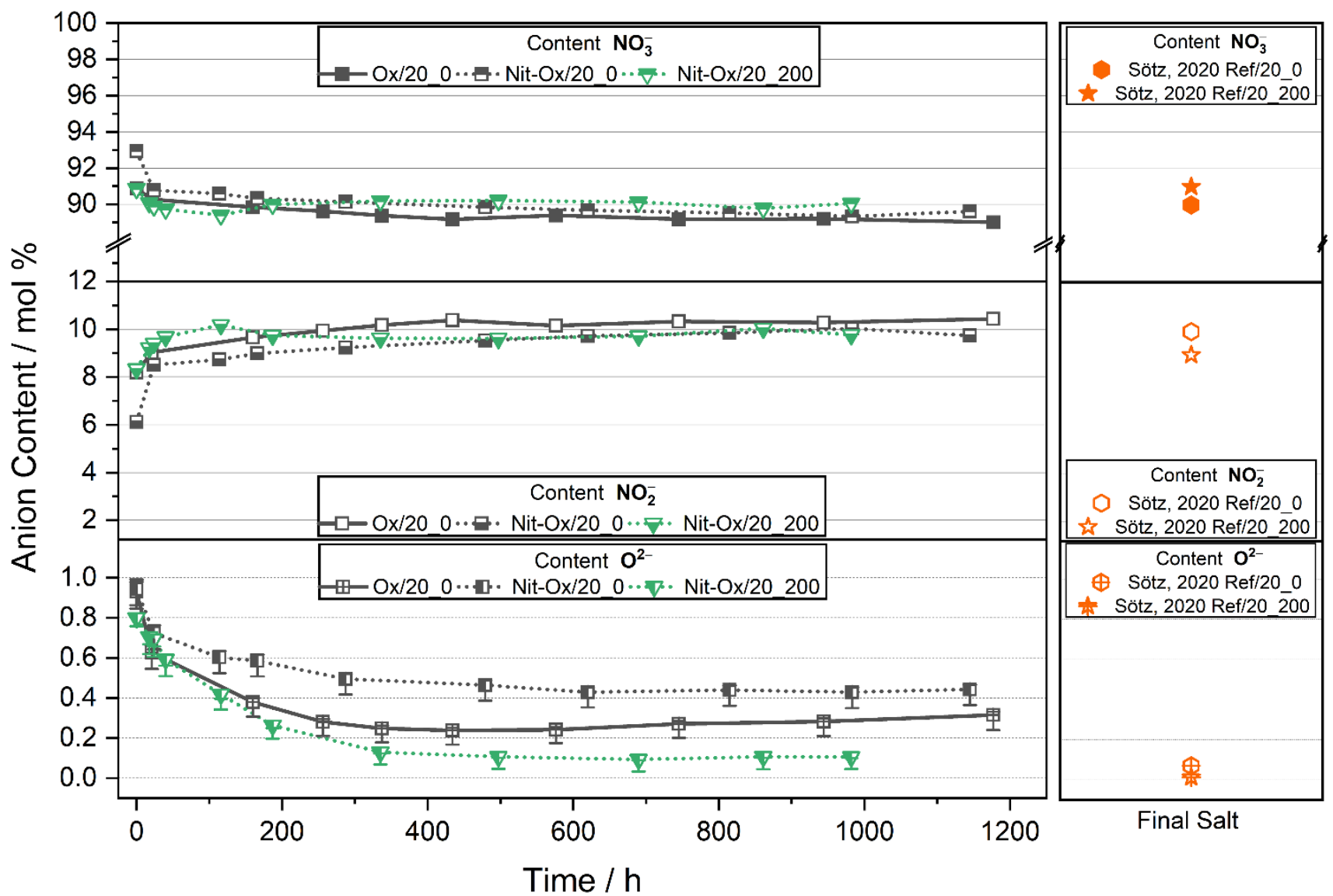

Figure 2. Content of nitrate, nitrite and oxide ions of investigated nitrate melts in this work with oxide addition. Literature data (orange symbols) shown (Ref/20_0, Ref/20_200) without oxide addition. All melts were stored under synthetic air with/without 200 ppm NO indicated by the label. Error bars not visible are within symbol size.

The oxide ion concentrations of the molten salt samples (Ox/20_0, Nit-Ox/20_200, Nit-Ox/20_0; Figure 2) decreased steadily during the first $400 \mathrm{~h}$, before they stabilized at $0.3,0.1$ and $0.4 \mathrm{~mol} \%$, respectively. It is in contrast to our expectation that the oxide ion concentrations decrease if no NO-gas is present in the purge gas. Further salt analysis, however, indicated that the oxide ions were consumed in a concurrent reac- 
tion with the stirrer (see next chapter). At a later stage of the experiments, the oxide ion concentrations began to diverge. For molten salt without NO purge (Ox/20_0), the oxide content started to increase again after $400 \mathrm{~h}$. This process was not observed for Nit-Ox/20_0, where the oxide ion content did not drop as low as in the Ox/20_0 experiment and remained constant at $0.44(+0.01-0.02) \mathrm{mol} \%$. Molten salt purged with $200 \mathrm{ppm}$ NO (Nit-Ox/20_200) comprised about a tenth of its initial oxide concentration after $400 \mathrm{~h}$, approximately $0.11(+0.01-0.02) \mathrm{mol} \%$ after $\mathrm{t}=1125 \mathrm{~h}$.

These findings allow for some remarks on the interaction of the gas phase and the oxide reaction equilibrium. The nitrate-nitrite equilibrium (Equation (1)) is most probably not directly affected by the presence of nitrous gas, and thus equilibrium levels for nitrate and nitrite are similar to published equilibrium data without additional oxide ions (Ref/20_0). In contrast to our expectation, for experiments with the addition of nitrite (Nit-Ox/20_0, Nit-Ox/20_200) the initial nitrite ion concentration after heating to the target temperature (at $\mathrm{t}=0 \mathrm{~h}$ ) was below $10 \mathrm{~mol} \%$. Presumably this is the case due to the occurrence of catalytic reactions involving the oxide ions and the oxidation of nitrite during the heating process, as it has been reported elsewhere [17]. The results point to the probability that with the presence of oxide ions, the effect of temperature and $\mathrm{p}\left(\mathrm{O}_{2}\right)$ on nitrate-nitrite reactions is occurring more rapidly. As the focus of this study was on equilibrium reactions at $600{ }^{\circ} \mathrm{C}$, we are aware that interpretations of reaction kinetics must be done with great caution and qualitatively only.

Close examination of the oxide content reveals that the molten salts in each of the three experiments follow a different reaction mechanism. For Nit-Ox/20_200 with nitrite and oxide addition and $\mathrm{NO}$ in the purge gas, the molten salt is first regenerated, as expressed by a significant reduction of the oxide ion concentrations. Subsequently, the oxide level is in equilibrium (unchanged), which can be attributed to the presence of NO in the atmosphere. It is reasonable to assume that the oxide ions are regenerated by the back reaction of Equation (2). This effect is visible in the nitrite content of Nit-Ox/20_200 having a maximum value after $116 \mathrm{~h}$ (Figure 2), which is not the case for molten salts purged with synthetic air (Ox/20_0, Nit-Ox/20_0). Compared to the literature experiment from Sötz et al. (Ref/20_200), the oxide ion equilibrium concentration at the end of the experiment of Nit-Ox-20_200 is somewhat higher ( $0.006 \mathrm{~mol} \%$ vs. $0.11 \mathrm{~mol} \%)$. In the case of the Ox/20_0 experiment with no $\mathrm{NO}$ in the gas stream, the nitrous gases evolving from the melt are constantly purged out of the crucible, resulting in $\mathrm{p}(\mathrm{NO})$ being effectively zero and therefore not allowing for any chemical equilibrium of Equation (2). The high but constant oxide ion content in Nit-Ox/20_0, is somewhat confounding, but could be explained as the result of a kinetic effect. Compared to Ref/20_0, the oxide content in our experiment is four times higher. Thus, with respect to Equation (2), nitrite decomposition is less favorable, slowed down, and the melt appears stabilized. It is possible that longer experimental durations would show an increasing oxide ion concentration of the Nit-Ox/20_0 experiment as a result of ongoing nitrite decomposition.

The second set of experiments was performed with oxygen rich purge gas $\left(\mathrm{p}\left(\mathrm{O}_{2}\right)=0.8 \mathrm{~atm}\right)$ are reduce nitrate decomposition and consequently study its effect on the oxide equilibrium. Similar to the previously discussed set of experiments at $\mathrm{p}\left(\mathrm{O}_{2}\right)=0.8 \mathrm{~atm}$ all of the experiments reach nitrate-nitrite-equilibrium with a ratio close to Ref/80_0 (Figure 3, orange). Furthermore, nitrite addition did not influence the final equilibrium values. All experiments with artificially added oxides showed a decrease of oxide concentration over time.

In the reference experiment (Ref/80_0) with pure Solar Salt (Figure 3, orange) the nitrite content increased before it reached a steady state at $6.0( \pm 0.1) \mathrm{mol} \%$, while the nitrate content stabilized at $93.9( \pm 0.1) \mathrm{mol} \%$. This result is consistent with thermodynamic expectations (93.3( \pm 0.3$): 6.7( \pm 0.1) \mathrm{mol}_{0} \mathrm{NO}_{3}{ }^{-}: \mathrm{NO}_{2}{ }^{-}$[7]) and in agreement with Equation (1), where increasing the oxygen partial pressure will push equilibrium composition to the nitrate side, thereby lowering the nitrite content. The detected oxide ion concentration increased continuously, with a final value of $0.14(+0.01-0.02) \mathrm{mol} \%$ at $1150 \mathrm{~h}$. This 
behavior is again explained by the fact that all gases evolving from the molten salt are purged out of the test rig, allowing no equilibration of Equation (2).

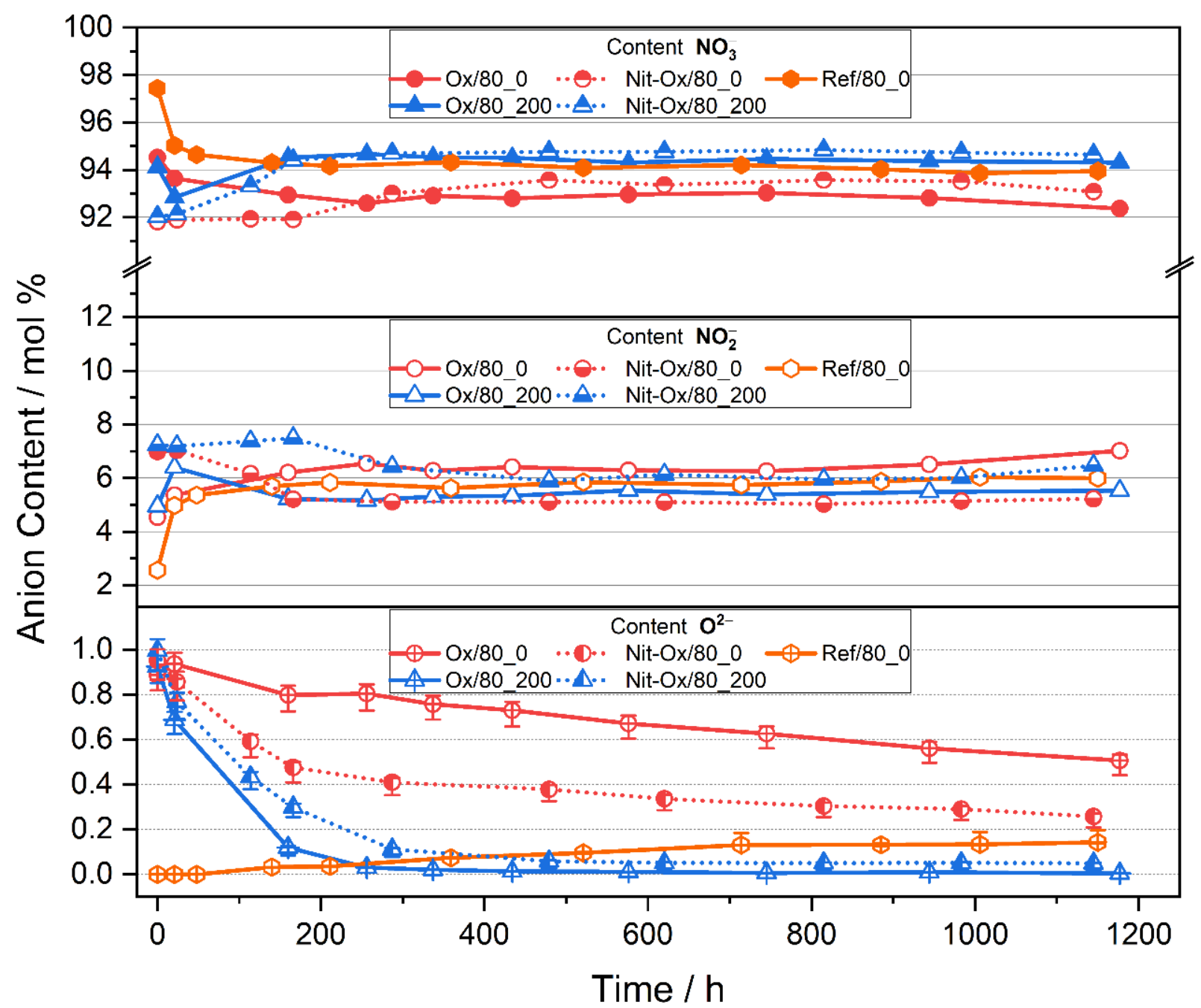

Figure 3. Content of nitrate, nitrite and oxide ions of investigated nitrate melts. Reference data shown (Ref/80_0) did not contain oxide dopant. Salts were stored under $0.8 \mathrm{~atm} \mathrm{O}_{2}$ with/without $200 \mathrm{ppm} \mathrm{NO}$ and with/without added nitrite indicated by the label. Error bars not visible are within symbol size.

For experiments without $\mathrm{NO}$ in the atmosphere and added oxides, the oxide ion content of Ox/80_0, Nit-Ox/80_0 decreased over the course of the experiments, mainly due to consumption of those ions during corrosion reactions. With the appliance of a purge gas containing $\mathrm{NO}$, the oxide ion content was significantly lower compared to experiments without NO. Detected values were as low as 0.05( \pm 0.01$) \mathrm{mol} \%$ for Nit-Ox/80_200 and below the detection limit $(<0.01 \mathrm{~mol} \%)$ for Ox/80_200. Rapid regeneration again resulted in a temporary increase of the nitrite content during the early stages of the experiments. This can be seen for experiment Nit-Ox/80_200 and Ox/80_200 after 21 and $166 \mathrm{~h}$, respectively.

It is worth mentioning that the oxide ion equilibrium level under $0.8 \mathrm{~atm} \mathrm{O}_{2}$ (Figure 3, Nit-Ox/80_200 with a value of $0.05( \pm 0.01) \mathrm{mol} \%$ at the end of the experiment $)$ is about half compared to $0.2 \mathrm{~atm} \mathrm{O}_{2}$ purge (Figure 2, Nit-Ox/20_200 with a value of $0.11(+0.01-0.02)$ $\mathrm{mol} \%$ at the end of the experiment). This demonstrates that by reducing the equilibrium content of nitrite from about $10 \mathrm{~mol} \%\left(\mathrm{p}\left(\mathrm{O}_{2}\right)=0.2 \mathrm{~atm}\right)$ to $6 \mathrm{~mol} \%\left(\mathrm{p}\left(\mathrm{O}_{2}\right)=0.8 \mathrm{~atm}\right)$, the equilibrium oxide ion content is also decreased. It is concluded in this work that the oxygen partial pressure indirectly controls nitrite decomposition to oxides. 


\subsection{Indicators for Corrosivity in an Oxide Rich Nitrate Melt}

The addition of sodium peroxide significantly altered the chemical properties of Solar Salt. In our experiments, the shaft of the stainless steel stirrer suffered from corrosion attack through the oxide ion. We utilized the detection rate of chromate as a qualitative indicator for the apparent corrosivity of our molten salts [18]. Molten salt without the addition of oxide ions (Ref/80_0) did not contain detectable chromates and the salt remained colorless over the course of the experiment. In contrast, experiments containing oxide ions showed steeply increasing chromate concentrations to approximately $0.1 \mathrm{~mol} \%$, within the first $200 \mathrm{~h}$ (Figure $4 \mathrm{~b}$ ), indicating high corrosivity compared to experiments without oxide addition. The salt samples containing even moderate concentrations of chromates exhibited a bright yellow or yellow/green color (Figure 4a).

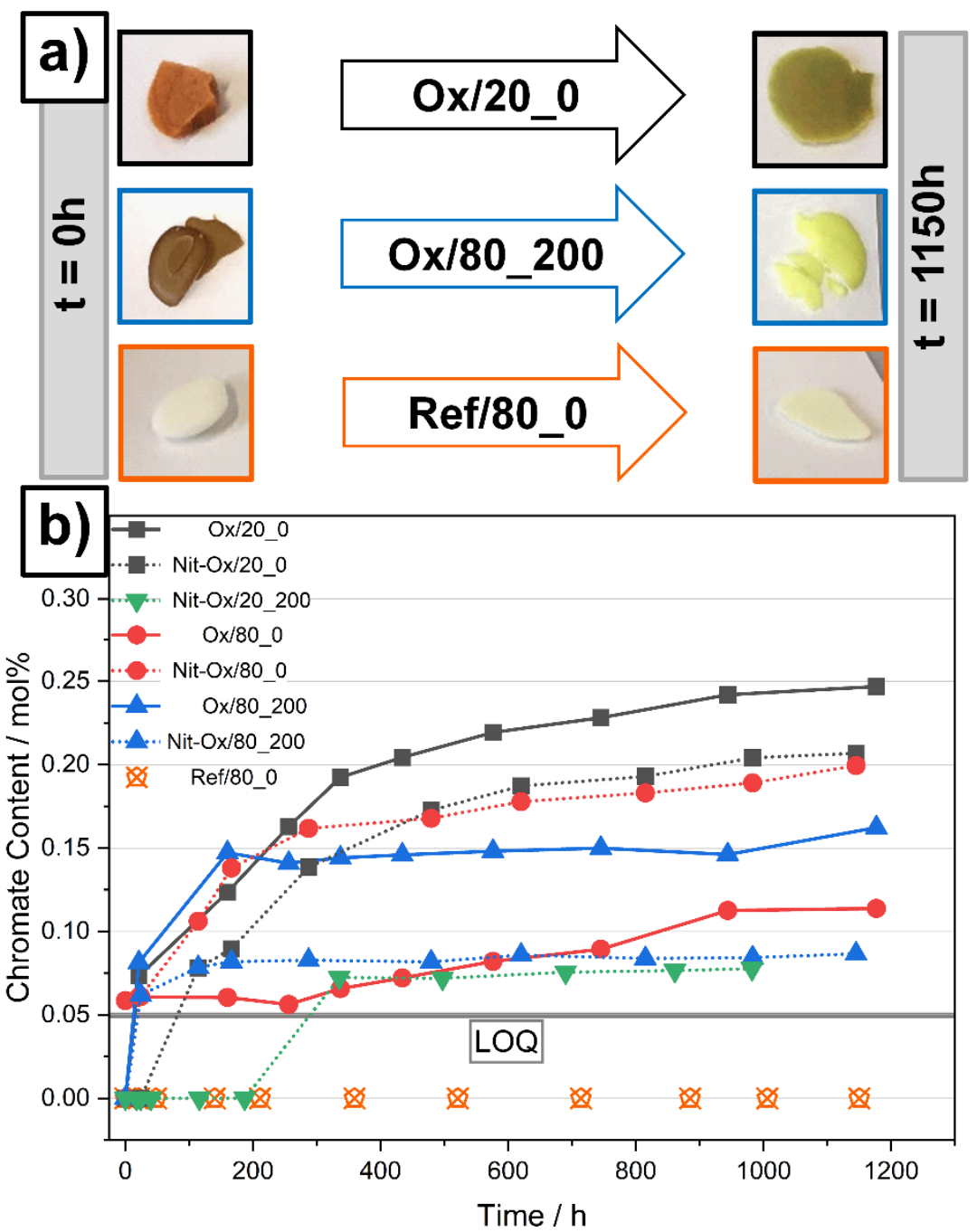

Figure 4. (a) Salt sample appearance initially $(t=0 \mathrm{~h})$ and at the end of the experiments $(t=1150 \mathrm{~h})$; (b) Chromate content over time of the molten salts. Limit of quantification (LOQ) indicated as gray bar. Reference data shown (Ref/80_0) did not contain oxide impurity. Error bars lay inside symbol.

Apart from chromium impurities, iron was also detected (up to $70 \mathrm{ppm}$ ) in some of the salt samples which contained oxide ions (see Table S4). By comparing the sample appearance depicted in (Figure 4a), a brown/green color (Ox/20_0, Ox/80_200) is a sign for transition metal impurities (e.g., $\mathrm{Fe}, \mathrm{Cr}$ ) dissolved in the salt $[14,19,20]$. Because corrosion reactions consume oxide ions and the investigated oxide ion regeneration process is taking place at the same time, great caution was necessary for the interpretation of oxide equilibrium data (Figures 2 and 3). However, during experiments with NO purge, the chromate 
levels stabilized, which indicates that corrosion reactions stopped at some point (e.g., experiments Ox/80_200, Nit-Ox/80_200 and Nit-Ox/20_200) and oxide ion equilibrium data was collected. It can be concluded that the regeneration of aged molten salt suppressed the release of transition metal impurities most likely originating from corrosion reactions. An extensive corrosion study needs to be conducted in order to generate quantitative data on this effect, and that was not within the scope of this investigation.

\section{Conclusions}

In this study, we demonstrated the regeneration of a decomposed oxide ion rich molten Solar Salt towards literature known equilibrium levels with a very low concentration of oxides under synthetic air conditions and 200 ppm NO. Additionally, the regeneration under $\mathrm{p}\left(\mathrm{O}_{2}\right)=0.8 \mathrm{~atm}$ lead to even lower oxide equilibrium levels and this showed the indirect influence of $\mathrm{p}_{\mathrm{O} 2}$ on the oxide formation mechanism. Our data reveals the entire capability of the nitrous gas purge to recover an aged molten Solar Salt towards Solar Salt equilibrium composition at $600{ }^{\circ} \mathrm{C}$ in terms of anion content. On the basis of literature investigations, thermophysical properties, which are directly dependent on salt composition, were conserved $[19,20]$. This work gives valuable experimental data on the oxide equilibrium concentration in Solar Salt under different atmospheres. Furthermore, for storage applications at current $\left(565^{\circ} \mathrm{C}\right)$ and potentially higher operation temperatures $\left(>565^{\circ} \mathrm{C}\right)$, our study is crucial for stable operation of Solar Salt beyond the current operation temperature and innovative salt recovery strategies of decomposed Solar Salt. Additionally, we have shown that at $600{ }^{\circ} \mathrm{C}$, molten Solar Salt with high oxide concentration significantly attacks steel components. By purging the molten salt with $\mathrm{NO}$ rich gas, the release of transition metal impurities potentially originating from corrosion reactions was retarded. However, given the short duration and varying steel surface quality in our experiments, caution must be applied when interpreting the data. Research into answering the question of a positive effect of NO purge and corrosion process reduction is already in progress.

Supplementary Materials: The following are available online at https:/ /www.mdpi.com/article/10 .3390/ma14195664/s1, Table S1: Titration error sources. Table S2: Ion chromatography error sources. Table S3: Maximum relative measuring uncertainty with respect to quadratic error propagation for molar ion content. Table S4: Iron content in nitrate salt samples after different exposure times. Images of the respective samples are presented for clarity.

Author Contributions: Conceptualization, J.S. and A.B.; Funding acquisition, A.B. and T.B.; Investigation, J.S.; Methodology, J.S. and V.A.S.; Project administration, A.B. and T.B.; Resources, J.S.; Supervision, J.S. and A.B.; Validation, J.S., V.A.S. and A.B.; Visualization, J.S.; Writing—original draft, J.S.; Writing - review \& editing, A.B., V.A.S. and T.B. All authors have read and agreed to the published version of the manuscript.

Funding: This research was funded by the German Federal Ministry for Economic Affairs and Energy (BMWi) in the VeNiTe project (Contract No. 03EE5043).

Institutional Review Board Statement: Not applicable.

Informed Consent Statement: Not applicable.

Data Availability Statement: The data presented in this study are available on request from the corresponding authors.

Acknowledgments: We kindly thank in particular Markus Braun and Andrea Hanke for technical work and great expertise in experimental methods.

Conflicts of Interest: The authors declare that they have no known competing financial interests or personal relationships that could have appeared to influence the work reported in this paper. 


\section{References}

1. Durth, M.; Prieto, C.; Rodriguez-Sanchez, A.; Patino-Rodriguez, D.; Cabeza, L.F. Effects of sodium nitrate concentration on thermophysical properties of solar salts and on the thermal energy storage cost. Sol. Energy 2019, 182, 57-63. [CrossRef]

2. Bauer, T.; Pfleger, N.; Laing, D.; Steinmann, W.-D.; Eck, M.; Kaesche, S. High-temperature molten salts for solar power application. In Molten Salts Chemistry; Elsevier: Amsterdam, The Netherlands, 2013; pp. 415-438.

3. Stern, K.H. High temperature properties and decomposition of inorganic salts part 3, nitrates and nitrites. J. Phys. Chem. Ref. Data 1972, 1, 747-772. [CrossRef]

4. Nissen, D.A.; Meeker, D.E. Nitrate/nitrite chemistry in sodium nitrate-potassium nitrate melts. Inorg. Chem. 1983, 22, 716-721. [CrossRef]

5. Wright, S.; Tran, T.; Chen, C.; Olivares, R.I.; Sun, S. Thermal Stability of Potassium and Sodium Nitrate Molten Salt Mixtures Above $500{ }^{\circ} \mathrm{C}$. In Proceedings of the Ninth International Conference on Molten Slags, Fluxes and Salts, Beijing, China, $27-30$ May 2012.

6. Mohammad, M.B.; Brooks, G.A.; Rhamdhani, M.A. Premelting, Melting, and Degradation Properties of Molten Alkali Nitrates: $\mathrm{LiNO}_{3}, \mathrm{NaNO}_{3}, \mathrm{KNO}_{3}$, and Binary $\mathrm{NaNO}_{3}-\mathrm{KNO}_{3}$. Metall. Mater. Trans. B 2018, 49, 1482-1498. [CrossRef]

7. Sotz, V.A.; Bonk, A.; Steinbrecher, J.; Bauer, T. Defined purge gas composition stabilizes molten nitrate salt-Experimental prove and thermodynamic calculations. Sol. Energy 2020, 211, 453-462. [CrossRef]

8. Fei, Z.; Zhang, Y.; Ge, M.; Wang, Y.; Li, Y.; Cheng, J.; Wei, B.; Hou, H.; Liu, H. Probing thermal decomposition mechanism of molten nitrite/nitrates salt by time of flight mass spectrometry. Sol. Energy 2019, 183, 823-828. [CrossRef]

9. Freeman, E.S. The kinetics of the thermal decomposition of sodium nitrate and of the reaction between sodium nitrite and oxygen. J. Phys. Chem. 1956, 60, 1487-1493. [CrossRef]

10. Bonk, A.; Martin, C.; Braun, M.; Bauer, T. Material Investigations on the Thermal Stability of Solar Salt and Potential Filler Materials for Molten Salt Storage. AIP Conf. Proc. 2017, 1850, 080008. [CrossRef]

11. Sötz, V.A.; Bonk, A.; Bauer, T. With a view to elevated operating temperatures in thermal energy storage-Reaction chemistry of Solar Salt up to $630^{\circ}$ C. Sol. Energy Mater. Sol. Cells 2020, 212, 110577. [CrossRef]

12. Fernandez, A.G.; Cabeza, L.F. Molten salt corrosion mechanisms of nitrate based thermal energy storage materials for concentrated solar power plants: A review. Sol. Energy Mater. Sol. Cells 2019, 194, 160-165. [CrossRef]

13. Nikulshina, V.; Ayesa, N.; Galvez, M.E.; Steinfeld, A. Feasibility of Na-based thermochemical cycles for the capture of $\mathrm{CO}_{2}$ from air-Thermodynamic and thermogravimetric analyses. Chem. Eng. J. 2008, 140, 62-70. [CrossRef]

14. Bonk, A.; Braun, M.; Hanke, A.; Forstner, J.; Rückle, D.; Kaesche, S.; Sötz, V.A.; Bauer, T. Influence of different atmospheres on molten salt chemistry and its effect on steel corrosion. AIP Conf. Proc. 2018, 2033, 090003. [CrossRef]

15. Sötz, V.A.; Bonk, A.; Forstner, J.; Bauer, T. Microkinetics of the reaction $\mathrm{NO}_{3}{ }^{-} \rightleftharpoons \mathrm{NO}_{2}{ }^{-}+0.5 \mathrm{O}_{2}$ in molten sodium nitrate and potassium nitrate salt. Thermochim. Acta 2019, 678, 178301. [CrossRef]

16. Tracey, T.R. Conceptual Design of Advanced Central Receiver Power System; Final Report; Martin Marietta Corp.: Denver, CO, USA, 1978.

17. Paniccia, F.; Zambonin, P.G. Redox mechanism in an ionic matrix. IV. Catalytic effects of peroxide and superoxide on the oxidation of nitrite by molecular oxygen in molten alkali nitrates. J. Phys. Chem. 1974, 78, 1693-1698. [CrossRef]

18. Federsel, K.; Wortmann, J.; Ladenberger, M. High-temperature and corrosion behavior of nitrate nitrite molten salt mixtures regarding their application in concentrating solar power plants. Enrgy Proced 2015, 69, 618-625. [CrossRef]

19. Villada, C.; Bonk, A.; Bauer, T.; Bolivar, F. High-temperature stability of nitrate/nitrite molten salt mixtures under different atmospheres. Appl. Energy 2018, 226, 107-115. [CrossRef]

20. Zhang, C.; Han, Y.; Wu, Y.; Lu, Y. Comparative study on high temperature thermal stability of quaternary nitrate-nitrite mixed salt and Solar salt. Sol. Energy Mater. Sol. Cells 2021, 230, 111197. [CrossRef] 